\title{
Dermoscopic features and types of orf and milker's nodule
}

\author{
Erhan Ayhan', Hamza Aktaş² \\ ${ }^{1}$ Department of Dermatology, Selahaddin Eyyubi State Hospital, Diyarbakır, Turkey \\ ${ }^{2}$ Department of Dermatology, Diyarbakır Ergani State Hospital, Diyarbakır, Turkey
}

Adv Dermatol Allergol 2017; XXXIV (4): 357-362

DOI: https://doi.org/10.5114/ada.2017.69317

\begin{abstract}
Introduction: Orf and milker's nodule are zoonotic cutaneous diseases generated by parapoxviruses. Contribution of dermoscopy to the diagnosis of these diseases has not been studied in the medical literature as to our knowledge. Aim: To investigate whether dermoscopy is a valuable diagnostic tool in orf and milker's nodule diagnosis or not. Material and methods: In this study, macroscopic and dermoscopic features have been evaluated by including 46 lesions of 32 patients who have orf and milker's nodule.

Results: $56.5 \%$ (26) of lesions were orf, while $43.5 \%$ (20) of lesions were milker's nodule (MN). Non-vascular dermoscopic structures have been determined as follows: blue-gray area ( $23.1 \%$ of orf, $35 \%$ of $M N$ ), orange-yellow streaks ( $19.2 \%$ of orf, $19.2 \%$ of $M N)$, grayish-whitish streaks ( $26.9 \%$ of orf, $55 \%$ of $M N)$, central yellow-white area $(26.9 \%$ of orf, $35 \%$ of $M N$ ), crust ( $46.2 \%$ of orf, $40 \%$ of $M N$ ), erosion-ulceration ( $69.2 \%$ of orf, $55 \%$ of $M N$ ), yellow-white globule (11.5\% of orf, $15 \%$ of $\mathrm{MN}$ ), and yellow-white ring ( $57.7 \%$ of orf, $35 \%$ of $\mathrm{MN})$. Limitations: Lack of PCR analysis, based of patient anamnesis types of orf and milker's nodule.

Conclusions: No significant dermoscopic differences have been determined between orf and milker's nodule patients' lesions. In our opinion, dermoscopy may be a useful tool to develop diagnosis of these diseases.
\end{abstract}

Key words: dermoscopy, orf, milker's nodule, infectious diseases, clinical features, dermoscopic types.

\section{Introduction}

Orf is a zoonotic disease formed by epitheliotropic DNA parapoxvirus that contaminates humans from infected goat and sheep [1]; whereas milker's nodule is an infection developed by paravaccinia virus and shown up in people who have contact with infected cattle's udder, body and oral cavity [2]. Erythematous, ulcerous, crusted, whitish and/or enclosed with erythematous ring papules and nodules may appear in each of two infections [2]. Also, those can be seen at locations like hands and fingers. Both parapoxviruses are similar as regards clinical and histopathological features. They are different only as to epidemiological ways [2].

\section{Aim}

In this study, findings that can help in diagnosis have been investigated by evaluating orf and milker's nodule dermoscopic features.

\section{Material and methods}

Thirty-two patients with 46 lesions whose ages show differences between 3 and 60, diagnosed as orf and milker's nodule and admitted to the Dermatology Department were included in this study. Biopsy has been taken from all lesions. Diagnosis of these diseases has been made based on clinical, histopathological features and having contact with the animal genus.

This study consists of three stages; determination of orf and milker's nodule lesion locations and dermoscopic analyses, photography and evaluation of findings.

Structures, determined at dermoscopic examination were classified as vascular and non-vascular ones.

All lesions in the study have been evaluated one by one, their features have been examined either macroscopically or dermoscopically by digital dermoscope (Fotofinder dermoscope II imaging system, TeachScreen Software $\mathrm{GmbH}$, Bad Birnbach, Germany; original magnification: 20x) and data were recorded. Three dermo-

Address for correspondence: Erhan Ayhan MD, Department of Dermatology, Selahaddin Eyyubi State Hospital, Diyarbakır, Turkey, phone: +90412 31750 98, fax: +90412 31740 15, e-mail: nanodunya@hotmail.com

Received: 22.08.2015, accepted: 1.05.2016. 
scopic images of each lesion were recorded, on average. $60 \%$ alcohol (ethanol) was used to flatten the skin, to increase the image quality by ensuring light to reach deeper decreasing.

\section{Statistical analysis}

All patient data were uploaded to SPSS 17.0 for Windows statistic application software. Data were analyzed by Pearson's $\chi^{2}$ test. It has been accepted as significant if $p$-value was below 0.05 .

\section{Results}

Thirty-two patients who have 46 lesions were included in the study. $46.8 \%$ (15) of patients were men, $53.2 \%$ (17) of patients were women. Average age of the patients was $32.4 \pm 13.9$ and it ranged from 3 to 60 years. The number of lesions was $1-4$, disease duration was 7-30 days in studied patients.

$56.5 \%$ (26) of lesions were orf, and $43.5 \%$ (20) of lesions were milker's nodule. Non-vascular structures observed at orf lesions at dermoscopy were sorted as follows: erosion-ulceration $(69.2 \%, 18)$, yellow-white ring $(57.7 \%, 15)$, crust $(46.2 \%, 12)$, grayish-whitish streaks $(26.9 \%, 7)$, central yellow-white area $(26.9 \%, 7)$, blue-gray area $(23.1 \%, 6)$, orange-yellow streaks $(19.2 \%, 5)$, and yellow-white globule $(11.5 \%, 3)$. Vascular structures were sorted as: erythema $(100 \%, 26)$, black dot $(65.4 \%, 17)$, erythematous ring $(61.5 \%, 16)$, dot vessels $(61.5 \%, 16)$,

Table 1. Dermoscopic structures in orf and milker's nodule

\begin{tabular}{lcc}
\hline Dermoscopic structures & Orf, $n$ (\%) & Milker's nodule, $n$ (\%) \\
\hline Erosion/ulceration & $18(69.2)$ & $11(55)$ \\
\hline Yellow-white ring & $15(57.7)$ & $7(35)$ \\
\hline Crust & $12(46.2)$ & $8(40)$ \\
\hline Grayish-whitish streaks & $7(26.9)$ & $11(55)$ \\
\hline Central yellow-white area & $7(26.9)$ & $7(35)$ \\
\hline Blue-gray area & $6(23.1)$ & $7(35)$ \\
\hline Orange-yellow streaks & $5(19.2)$ & $5(19.2)$ \\
\hline Yellow-white globule & $3(11.5)$ & $3(15)$ \\
\hline Vascular formations: & & $20(100)$ \\
\hline Erythema & $26(100)$ & $11(55)$ \\
\hline Black dot & $17(65.4)$ & $15(75)$ \\
\hline Erythematous ring & $16(61.5)$ & $12(60)$ \\
\hline Dot vessels & $6(61.5)$ & $3(15)$ \\
\hline Comma vessels & $5(19.2)$ & $3(15)$ \\
\hline Polymorphic vessels & $5(19.2)$ & $1(5)$ \\
\hline Glomerular vessels & $1(3.8)$ & $0(0)$ \\
\hline Hairpin vessels & $0(0)$ & \\
\hline Milky-red globule & & \\
\hline
\end{tabular}

comma vessels $(19.2 \%, 5)$, polymorphic vessels $(19.2 \%$, $5)$, glomerular vessels $(3.8 \%, 1)$, hairpin vessels $(0 \%, 0)$, and milky-red globule $(0 \%, 0)$.

Non-vascular structures observed in milker's nodule at dermoscopy were sorted as follows: erosion-ulceration $(55 \%, 11)$, grayish-whitish streaks $(55 \%, 11)$, crust $(40 \%, 8)$, central yellow-white area $(35 \%, 7)$, blue-gray area $(35 \%, 7)$, yellow-white ring $(35 \%, 7)$, orange-yellow streaks (19.2\%, 5), and yellow-white globule (\%15, 3). Vascular structures were sorted as erythema $(100 \%, 20)$, erythematous ring $(75 \%, 15)$, dot vessels $(60 \%, 12)$, black dot $(55 \%, 11)$, hairpin vessels $(15 \%, 3)$, comma vessels $(15 \%$, $3)$, milky-red globule $(10 \%, 2)$, polymorphic vessels (15\%, $3)$, and glomerular vessels $(5 \%, 1)$.

Vascular and non-vascular structures of all lesions are shown in Table 1.

Erythema multiforme was observed in $30.6 \%$ of patients who have milker's nodule while it was not observed in orf patients. Orange-yellow streaks and grayishwhitish streaks were usually observed together. This was statistically significant $(p<0.001)$.

\section{Discussion}

The designation "orf" is derived from the AngloSaxon name for cattle and is actually a misnomer for the disease which, though naturally occurring in sheep, goats, and camels [3], has never been reported in cattle. However, milker's nodule, an endemic pox virus disease in cows, presents with a clinical and histologic picture identical to that of orf [4] and has a similar viral ultrastructural appearance [5]. But there are some opinions that they include different histopathological features [6].

In our study, clinical and dermoscopic features of orf and milker's nodule were examined. Some similar clinical, epidemiological and dermoscopic findings were observed. Significant findings have not been observed at dermoscopic findings in both diseases.

Lesions were separated into 4 classes generally. They are a yellow-white area in the middle and erythematous ring around in type 1 (Figure 1), usually orange-yellow streaks in the center with violaceous erythematous base and grayish-whitish streaks around and the erythematous ring outside in type 2 (Figure 2), ulceration in the center, yellow-white ring around and erythema ring outside in type 3 (Figure 3), erythema in the center or ulcer-crusted area, yellow-white ring around in type 4 (Figure 4).

The central yellow-white area, one of the observed dermoscopic structures, has been seen in $26.9 \%$ of orf lesions and $35 \%$ of milker's nodule lesions. Squamous cell carcinoma and keratoacanthoma are the primary skin diseases among the diseases that show similar dermoscopic features in the center. These types of structures in these diseases are named as central mass of keratin and evaluated as a keratinization sign [7, 8]. An irregular, whitish-yellow amorphous structure in the center has 

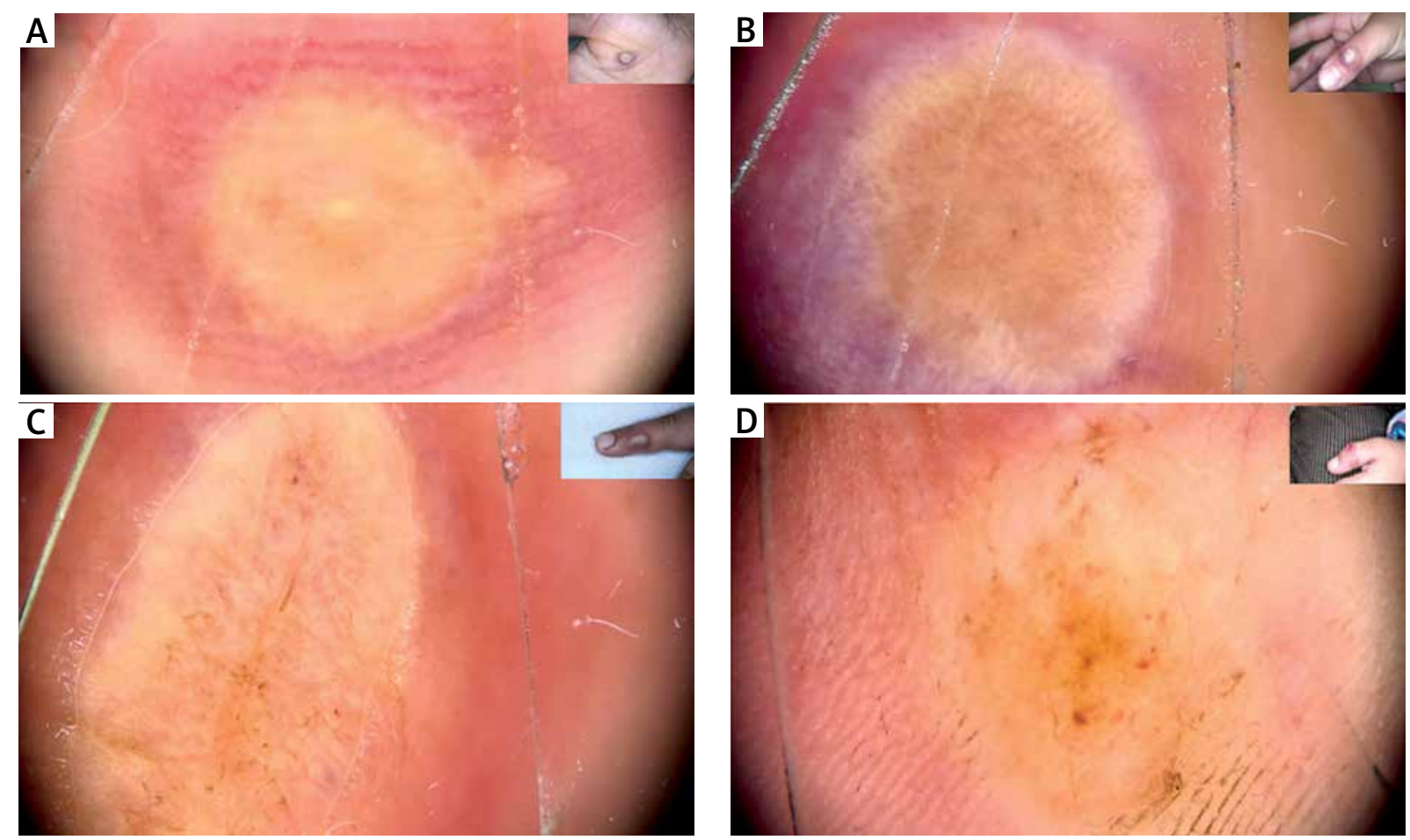

Figure 1. Milker's nodules (A, B, C) and orf (D) lesions. Type 1 lesions. Dermoscopy shows central yellow-white area (all of the lesions), erythematous ring (all of the lesions), black dot (B, C), dot vessels (D) and grayish-whitish steaks (B) (original magnification 10x)
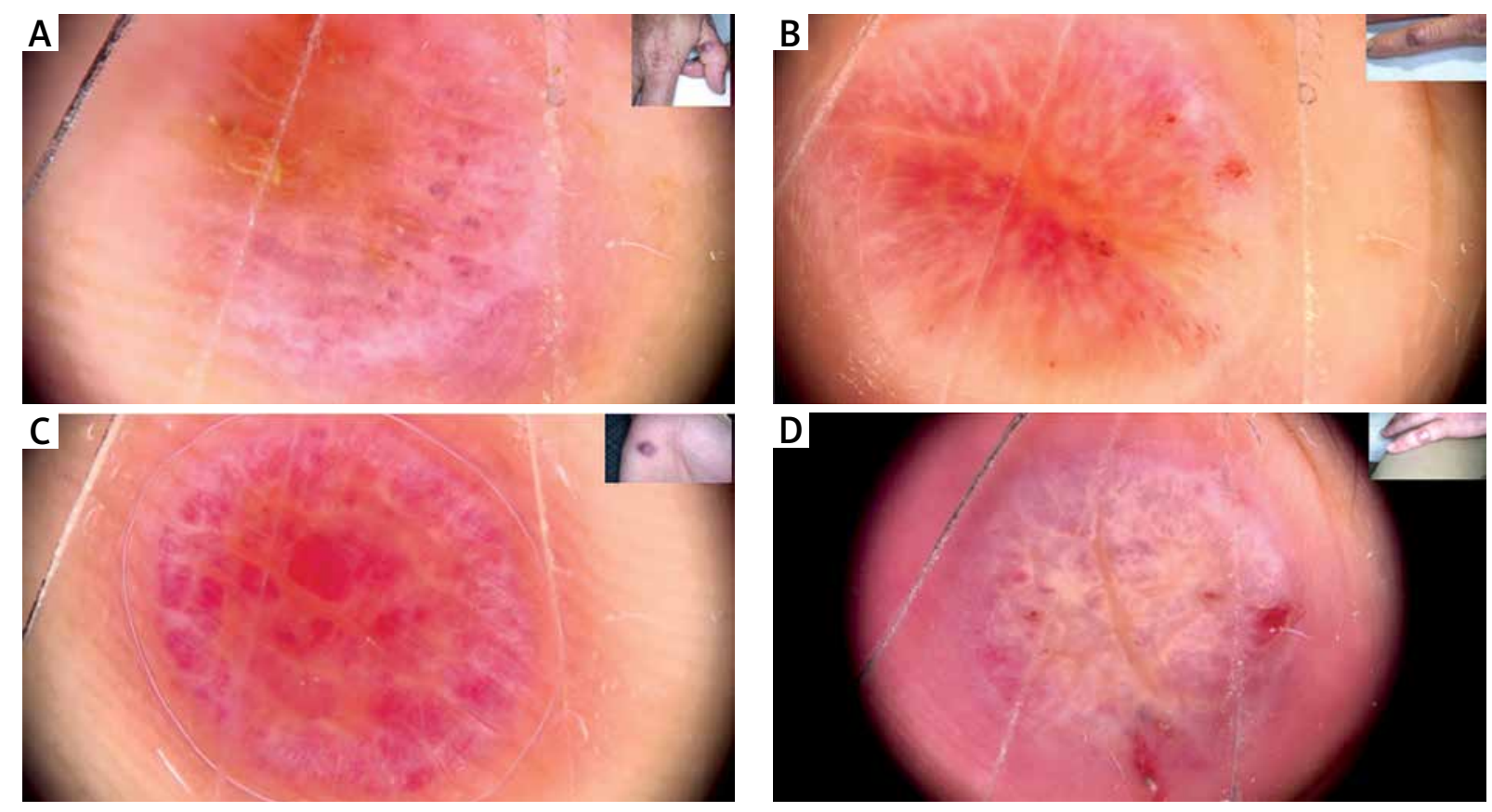

Figure 2. Milker's nodules (A, C) and orf (B, D) lesions. Type 2 lesions. Dermoscopy shows orange-yellow streaks (all of the lesions), grayish-whitish streaks (all of the lesions), black dot (A, B, D), blue-gray area (D), ulceration (B, D), milky-red globule (C), erythematous ring (C, D) (original magnification 10x)

been determined in a case of atypical pyogenic granuloma [9]. Dermoscopic structures, evaluated as orangeyellow streaks have been observed in equal proportions
(19.2\%) in both diseases. These structures are usually located in the center of lesions and have unspecific borders. One of other dermoscopic structures, grayish- 

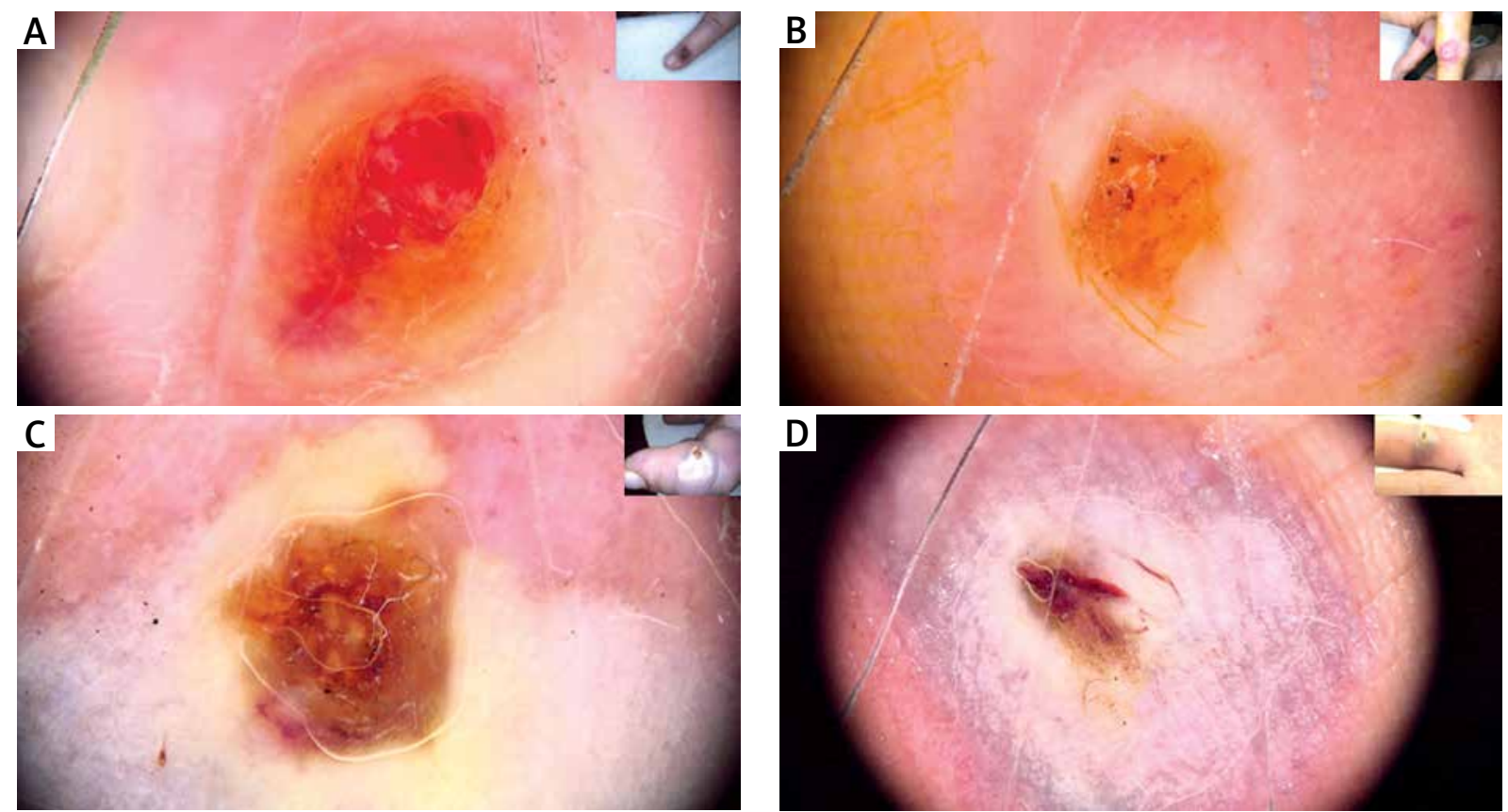

Figure 3. Orf lesions. Type 3 lesions. All of the lesions are ulceration, yellow-white ring, erythematous ring and black dot (original magnification 10x)
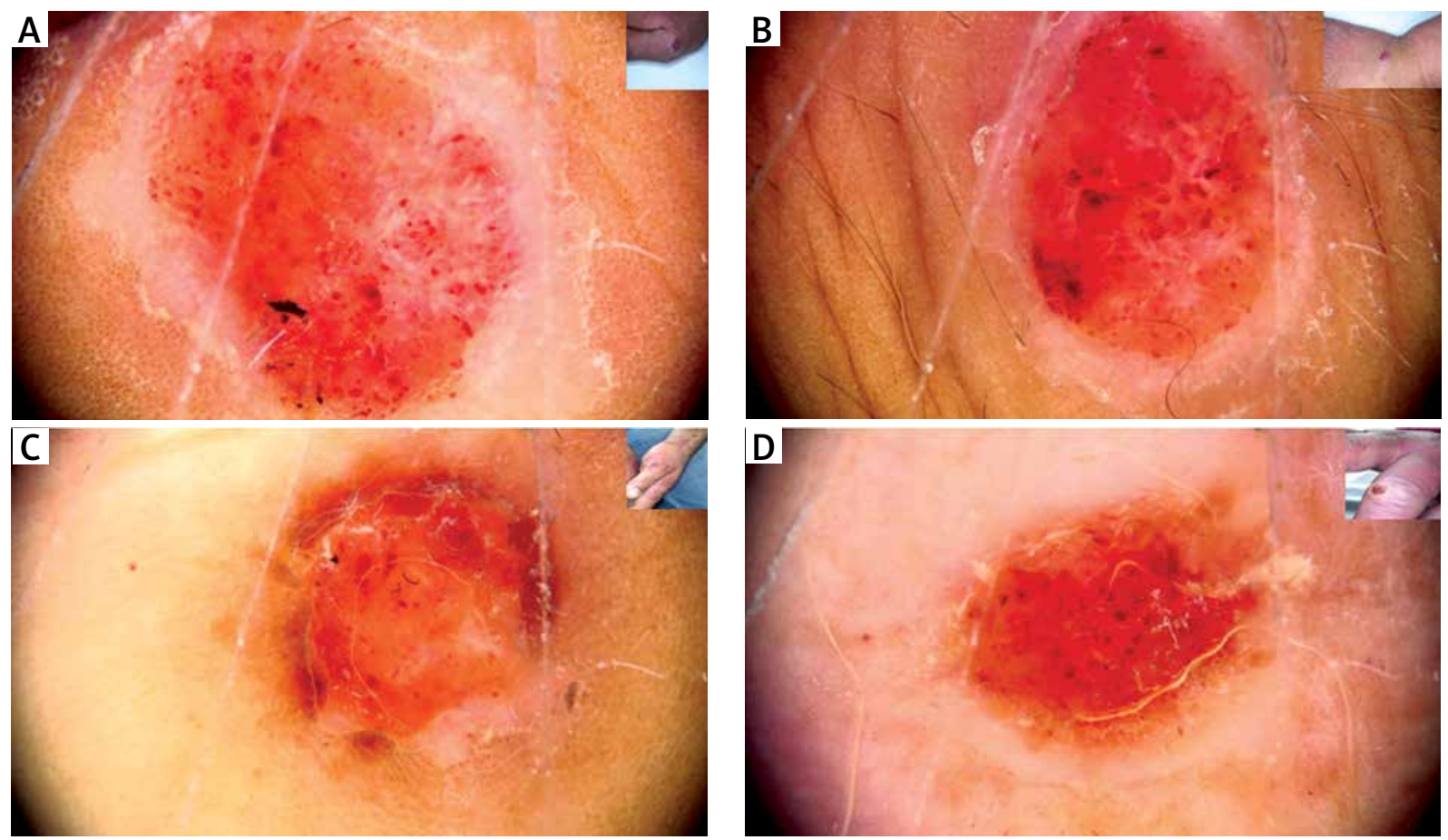

Figure 4. Milker's nodules (A, B) and orf (C, D) lesions. Type 4 lesions. Dermoscopy shows ulcerations, yellow-white ring, polymorphic vessels (predominated dot and comma vessels) in all of the lesions. Grayish-whitish streaks are seen in lesions of $A, B, C$ (original magnification 10x)

whitish streaks, has been determined as continuation of orange-yellow streaks. Dermoscopic structures like grayish-whitish streaks were determined at pilomatrixoma in the literature $[10,11]$. In a study by Zaballos et al., white streaks have been determined in $70 \%$ of 10 pilomatrixoma cases [10]. Similar structures have been observed in juvenile xanthogranuloma and lichen planus [11, 12]. White streaks structures have been encountered in pic- 
tures of a study about Merkel cell carcinoma although it has not been indicated [13]. Rates of blue-gray areas at orf and milker's lesions have not been determined as significant $(p=0.373)$. Dermoscopic formations similar to those structures are named as blue-gray globule at basal cell carcinoma and trichoepithelioma $[14,15]$. The bluegray area has been observed at a $20 \%$ rate in a study in which 10 pilomatrixoma cases have been evaluated [10]. Although they have similar shapes, in our opinion, bluegray areas observed in orf and milker's nodule depend on the hemorrhagic area which was formed in dermis. In our study, small, dot or splinter shaped hemorrhagic areas that may be observed macroscopically are named as black dot. These formations have been observed in high frequency in both diseases. Vascular formations which have been detected in dermoscopy become important in diagnosis of skin lesions recently. Six main morphological structures are identified among a variety of different vascular structures, namely comma-like, dotted, linear - irregular, hairpin-like, glomerular and arborizing vessels. In addition, there are three specific global structures, namely crown vessels which are located around a whitish core, strawberry vessels and milky red globules [16-19].

Dot vessels correspond to the tips of short and vertically arranged capillaries in lesions of smaller diameters and appear in dermoscopy as very small red dots with a diameter of 0.01 to $0.02 \mathrm{~mm}$. Such vessels may appear in many small and vertical diameter keratinized tumors such as verruca vulgaris, actinic keratosis, seborrheic keratosis, Bowen's disease (BD), squamous cell carcinoma (SCC) [20]. In our study, dot vessels has been detected in $61.5 \%$ of orf lesions, $60 \%$ of milker's nodules.

Comma-like vessels are slightly bended hardly arborizing vessels with a diameter of $1 \mathrm{~mm}$ or larger. Comma-like vessels are a variant of dotted and hairpin-like vessels which are some of the basic curved vascular structures [20]. Comma-like vessels is a differential dermoscopic feature in dermal nevus [21]. There are studies which report that $1-45 \%$ of all superficial and nodular types of basal cell carcinomas display comma-like vessels [22, 23]. Polymorphic vessels is a combination of two or more vascular patterns of different types. The most frequent combination is the one composed by linearirregular vessels and dotted vessels. This combination is quite specific to amelanotic/hypomelanotic melanoma of small and medium thickness, particularly when it is located at the core [24]. Furthermore, combinations of linear-irregular vessels and dotted vessels, particularly microarborizing vessels, were detected in Merkel cell carcinoma [13]. Dot vessels and comma-like vessels are the most frequent vascular combinations we have detected.

Erythema multiforme is one of the complications of orf and milker's nodule. It was much more reported at orf infections than milker's nodule. Erythema multiforme is thought to be a cell-mediated (delayed type) hypersensitivity reaction that can occur after exposure to certain infections and less commonly to drugs [1]. In our study, six erythema multiforme diseases have been observed in patients who only have milker's nodule.

\section{Conclusions}

As a result, orange-yellow streaks, grayish-whitish streaks, central yellow-white area, black dot, blue-gray area, crust, erosion-ulceration, erythematous ring, yellow-white ring, erythema, dot vessels are the most determined dermoscopic structures in orf and milker's nodule. Although these formations have been observed in different rates in both diseases, no statistically significant difference has been determined between them. Our opinion is dermoscopy can be a helpful tool for diagnosis even it cannot provide diagnosis of these diseases fully.

\section{Conflicts of interest}

The authors declare no conflict of interest.

\section{References}

1. Joseph RH, Haddad FA, Matthews AL, et al. Erythema multiforme after orf virus infection: a report of two cases and literature review. Epidemiol Infect 2014; 8: 1-6.

2. Barraviera SRCS. Diseases caused by poxvirus - orf and milker's nodules - a review. J Venom Anim Toxins Incl Trop Dis 2005; 11: 102-8.

3. Dashtseren T, Solovyev BA, Varejka F, et al. Camel contagious ecthyma (pustular dermatitis). Acta Virol 1984; 28: $122-7$.

4. Leavell U, Phillips I. Milker's nodules. Arch Dermatol 1975; 111: 1307-11.

5. Johannensen JV, Krogh HK, Solberg I, et al. Human orf. J Cutan Pathol 1975; 2: 265-83.

6. Groves RW, Wilson-Jones E, MacDonald DM. Human orf and milkers' nodule: a clinicopathologic study. J Am Acad Dermatol 1991; 25: 706-11.

7. Lin MJ, Pan Y, Jalilian C, et al. Dermoscopic characteristics of nodular squamous cell carcinoma and keratoacanthoma. Dermatol Pract Concept 2014; 4: 9-15.

8. Zalaudek I, Giacomel J, Schmid K, et al. Dermatoscopy of facial actinic keratosis, intraepidermal carcinoma, and invasive squamous cell carcinoma: a progression model. J Am Acad Dermatol 2012; 66: 589-97.

9. Lacarrubba F, Caltabiano R, Micali G. Dermoscopic and histological correlation of an atypical case of pyogenic granuloma. Pediatr Dermatol 2013; 30: 499-501.

10. Zaballos P, Llambrich A, Puig S, et al. Dermoscopic findings of pilomatricomas. Dermatology 2008; 217: 225-30.

11. Song M, Kim SH, Jung DS, et al. Structural correlations between dermoscopic and histopathological features of juvenile xanthogranuloma. J Eur Acad Dermatol Venereol 2011; 25: 259-63.

12. Tan C, Min ZS, Xue Y, et al. Spectrum of dermoscopic patterns in lichen planus: a case series from China. J Cutan Med Surg 2014; 18: 28-32.

13. Harting MS, Ludgate MW, Fullen DR, et al. Dermatoscopic vascular patterns in cutaneous Merkel cell carcinoma. J Am Acad Dermatol 2012; 66: 923-7. 
14. Lazaridou E, Fotiadou C, Patsatsi A, et al. Solitary trichoepithelioma in an 8-year-old child: clinical, dermoscopic and histopathologic findings. Dermatol Pract Concept 2014; 4: 55-8.

15. Puig S, Cecilia N, Malvehy J. Dermoscopic criteria and basal cell carcinoma. G Ital Dermatol Venereol 2012; 147: 135-40.

16. Kreusch J, Koch F. Incident light microscopic characterization of vascular patterns in skin. Hautarzt 1996; 47: 264-72.

17. Argenziano G, Zalaudek I, Corona R, et al. Vascular structures in skin tumors. A dermoscopy study. Arch Dermatol 2004; 140: 1485-9.

18. Zalaudek I, Argenziano G, Oliviero M, Rabinovitz H. Dermoscopy of nonpigmented skin tumors. In: Year Book of Dermatology and Dermatologic Surgery 2007. Thiers BH, Lang PG Jr (eds). Elsevier Mosby, Philadelphia 2007; 23-38.

19. Zalaudek I, Argenziano G, Di Stefani A, et al. Dermoscopy in general dermatology. Dermatology 2006; 212: 7-18.

20. Kreusch J. Vascular patterns in skin tumors. Clin Dermatol 2002; 20: 248-54.

21. Menzies SW, Westerhoff K, Rabinovitz H, et al. Surface microscopy of pigmented basal cell carcinoma. Arch Dermato 2000; 136: 1012-6.

22. Micantonio T, Gulia A, Altobelli E, et al. Vascular patterns in basal cell carcinoma. J Eur Acad Dermatol Venereol 2011; 25: 358-61.

23. Trigoni A, Lazaridou E, Apalla Z, et al. Dermoscopic features in the diagnosis of different types of basal cell carcinoma: a prospective analysis. Hippokratia 2012; 16: 29-34.

24. Menzies SW, Kreusch J, Byth K, et al. Dermoscopic evaluation of amelanotic and hypomelanotic melanoma. Arch Dermatol 2008; 144: 1120-7. 